\title{
Our experience in endoscopic management of mucormycosis: a case series and review of literature
}

\author{
Inderdeep Singh*, Vikas Gupta, Salil Kumar Gupta, Sunil Goyal, \\ Manoj Kumar, Anubhav Singh
}

Department of ENT, Command Hospital, Armed Forces Medical College, Pune, India

\author{
Received: 17 January 2017 \\ Revised: 01 March 2017 \\ Accepted: 06 March 2017

\section{*Correspondence:} \\ Dr. Inderdeep Singh, \\ E-mail: dridsingh@hotmail.com
}

Copyright: ( ) the author(s), publisher and licensee Medip Academy. This is an open-access article distributed under the terms of the Creative Commons Attribution Non-Commercial License, which permits unrestricted non-commercial use, distribution, and reproduction in any medium, provided the original work is properly cited.

\begin{abstract}
Sinonasal mucormycosis is uncommon entity and it rarely infects a healthy host. When it does occur; it becomes very difficult to treat because of the speed of progress of disease and can have fatal outcomes. The mainstays of therapy are treatment of immunocompromised status, systemic high dose Amphotericin B, and surgical debridement of necrosed or nonviable tissue. The following six cases, managed at our centre from July 2016 to October 2016, outline nuances in the diagnosis of invasive sinonasal mucormycosis and highlight the importance of timely surgical debridement and importance of endoscopic approach in complete clearance of disease in order to facilitate medical management to work. All cases included in this study were found to be immunocompromised and had unilateral severe diminution of vision due to periorbital extension of disease. Diagnostic nasal endoscopy revealed black-brown crust and tenacious pus filling up nasal cavity, erosion of turbinates and nasal septal perforation. One patient showed erosion of hard palate and eschar formation. CECT/MRI of PNS showed evidence of bony erosion and orbital involvement. Biopsy taken during nasal endoscopy confirmed the presence of mucormycosis. All patients were started on Liposomal Amphotericin B and broad spectrum antibiotics in renal corrected dosages and taken up for urgent endonasal endoscopic debridement. All paranasal sinuses were cleared and orbital decompression was done. Postoperatively all patients were continued on Liposomal Amphotericin B in renal corrected dosages for two-three weeks and being followed up monthly. One patient could not survive due to several co morbidities and severe immunocompromised status. Only one patient showed recurrence of disease on one month postoperative follow up. Five patients showed improvement in visual acuity. Sinonasal mucormycosis if inappropriately diagnosed and treated can be a fatal condition. Energetic diagnostic workup, combined with equally energetic management, surgical and management leads to favourable outcome.
\end{abstract}

Keywords: Sinonasal mucormycosis, Immunocompromised status, Endoscopic management, Mucormycosis

\section{INTRODUCTION}

Mucormycosis is a term used to refer to any fungal infections of the order Mucorales, which belongs to the class Zygomycetes. ${ }^{1}$ Sinonasal mucormycosis is uncommon entity and it rarely infects a healthy host, however once infected, it rapidly progresses which at times is difficult to treat and can be fatal. If unrecognized or inadequately treated, it is known to be most acutely fatal infection known in medical literature. It afflicts primarily diabetics with uncontrolled glycemic status, but can occur in any immunocompromised individual, and on rare occasions can infect normal hosts as well. ${ }^{1}$ It can involve upper aerodigestive tract, lungs, central nervous system, gastrointestinal tract and skin (usually in burn patients). Most fatal presentation is rhino-cerebral 
involvement, which is usually initiated with paranasal sinus involvement and may progress to the orbit and the brain. ${ }^{1}$ Loss of vision is one of the dreaded complications apart from fatality.

Intraoperative nasal endoscopic examination is the most informative test for possible fungal involvement of nasal cavity and paranasal sinuses. $^{2}$ The mainstays of therapy are treatment of immunocompromised status, systemic high dose Amphotericin B, and surgical debridement of necrosed or nonviable tissue. ${ }^{3}$

Following cases highlight the importance or early diagnosis governed by endonasal endoscopic examination and surgical decision of endoscopic management of mucormycosis, resulting in favourable outcome and lesser complications, especially pertaining to vision.

\section{CLINICAL DATA}

\section{Patient information}

We retrospectively reviewed data of our six patients managed in a short span of four months, ranging from 40 -71 years (median age of 62 year). All cases were immunocompromised in form of having uncontrolled diabetes mellitus, chronic kidney disease, leading to sepsis. One patient was a renal transplant recipient on immunosuppressive treatment. Our patients presented with symptoms ranging from high grade fever not controlled on broad spectrum parenteral antibiotics, facial swelling and pain, peri orbital oedema, diminished or loss of vision, ophthalmoplegia, proptosis, palatal ulcer, and purulent discharge from nose. The renal transplant recipient patient also had lower cranial nerve palsies apart from above mentioned symptoms and signs. However no patient was suffering from HIV, Hepatitis B, Hepatitis C, or malignancy.

\section{Workup}

All patients underwent urgent rigid nasal endoscopy which revealed black brown crusts which did not bleed on removal and tenacious pus filling left nasal cavity, appearing to be arising from middle meatus. There was erosion of middle turbinate (left) and posterior end of inferior turbinate (left) with posterior septal perforation. Examination of oral cavity revealed perforation of hard palate with black eschar formation in one patient. There was erosion of lamina papyracea in three patients, with invasion of periorbital fat in two patients as presented in Figure 1A-1D. Biopsy was taken in all cases which was positive for mucormycosis. All patients also underwent ophthalmologic examination, in view of diminished or loss of vision. The distant visual acuity ranged from 6/36 to complete loss of vision in affected eye.

CT / MRI scan of PNS was done in all cases to determine the extent of infection as depicted in Figure 2A-2C. Apart of these routine complete blood counts, various other biochemical and serological tests were performed. All patients had neutropenia, grossly deranged glycemic control, and deranged serum urea and creatinine values suggestive of chronic kidney disease.
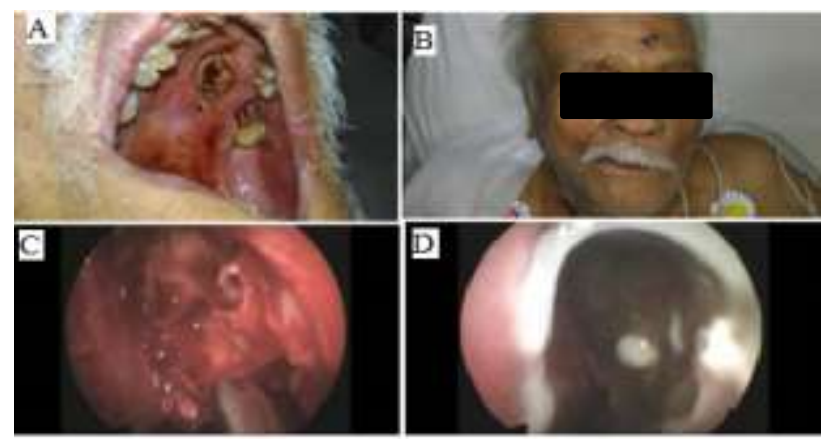

Figure 1: A) Preoperative picture of patient showing left hemifacial swelling, periorbital oedema and proptosis. B) Palatal ulcer with eschar. C) Endoscopic picture of left nasal cavity showing black crusts with pus. D) Complete debridement of all sinuses with necrosed inferior and middle turbinates (left).

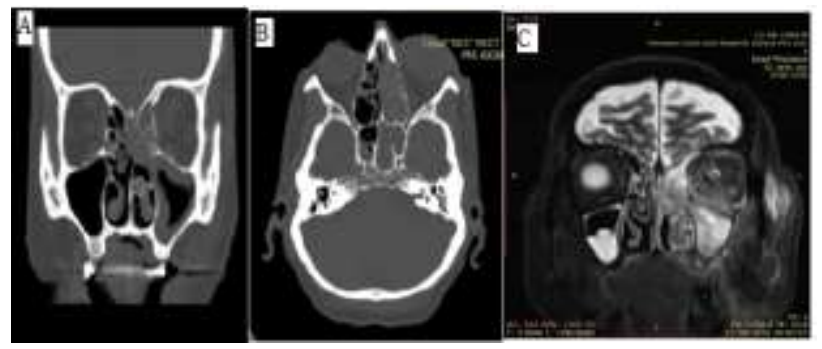

Figure 2: NCCT Paranasal sinuses. A) Soft tissue attenuation density shadow involving bilateral maxillary, ethmoidal and sphenoid sinuses as well as involvement of left periorbital tissue displacing orbit laterally and anteriorly. Medial rectus (left) seems to be inflamed. B) Soft tissue attenuation density shadow involvement of anterior part of left maxillary sinus blocking osteomeatal complex and anterior ethmoidal cells extending in left orbit with evidence of bony erosion of medial orbital wall and thickening of medial rectus muscle (left). C) MRI brain and PNS T2 weighted coronal section showing heterogeneous altered hyperintense signal intensity enhancing soft tissue thickening completely involving left maxillary, ethmoids and frontal sinus with left intraorbital extension involving extraconal tissue along the inferior-medial orbital wall near origin of the medial rectus muscle (left). Right maxillary and ethmoidal sinuses are partially involved.

\section{Treatment}

All patients were put on broad spectrum parenteral antibiotics covering gram positive, negative, and anaerobic bacteria in renal corrected dosages. Liposomal Amphotericin B was also started in renal modified dosages in consultation with our Nephrologist. 
Table 1: Salient features of patients.

\begin{tabular}{|c|c|c|c|c|c|c|c|c|c|}
\hline S. No & Age & Gender & $\begin{array}{l}\text { Duration } \\
\text { of } \\
\text { symptoms }\end{array}$ & Clinical presentation & $\begin{array}{l}\text { Predisposin } \\
\mathrm{g} \text { factors }\end{array}$ & Management & Eye sight improvement-post surgery & Mortality & $\begin{array}{l}\text { Follow up at } 3 \\
\text { months }\end{array}$ \\
\hline 01 & $40 y$ & Female & 20 days & $\begin{array}{l}\text { Fever, Nasal obstruction, } \\
\text { hemifacial swelling, } \\
\text { headache, Periorbital oedema, } \\
\text { Retrorbital pain, loss of vision } \\
\text { Left eye }\end{array}$ & $\begin{array}{l}\text { Diabetes } \\
\text { mellitus }\end{array}$ & $\begin{array}{l}\text { Endonasal Endoscopic } \\
\text { Powered debridement with } \\
\text { Intravenous Liposomal } \\
\text { Amp B in renal corrected } \\
\text { dosage }\end{array}$ & $\begin{array}{l}\text { Preop- Total blindness, due to Central } \\
\text { Retinal Artery thrombosis } \\
\text { Postoperative - No improvement }\end{array}$ & No & Free of disease \\
\hline 02 & $68 \mathrm{y}$ & Male & 15 days & $\begin{array}{l}\text { Fever, Facial swelling } \\
\text { opthalmoplegia, Proptosis } \\
\text { Left eye, lower cranial nerve } \\
\text { palsies. Oral ulceration and } \\
\text { eschar. Patient in moribund } \\
\text { condition. }\end{array}$ & $\begin{array}{l}\text { Diabetes } \\
\text { mellitus, } \\
\text { immuno } \\
\text { compromise } \\
\text { d renal } \\
\text { transplant } \\
\text { recipient }\end{array}$ & - do- & $\begin{array}{l}\text { Preop - total blindness } \\
\text { Postop - No improvement }\end{array}$ & $\begin{array}{l}\text { Yes, } \\
\text { patient } \\
\text { expired } \\
\text { due to } \\
\text { fulminant } \\
\text { sepsis } \\
\text { following } \\
02 \text { weeks } \\
\text { of surgery }\end{array}$ & \\
\hline $\mathbf{0 3}$ & $60 y$ & Female & 07 days & $\begin{array}{l}\text { Fever, Nasal obstruction, } \\
\text { nasal discharge, Hemifacial } \\
\text { headache, hemifacial swelling } \\
\text { and tenderness, periorbital } \\
\text { oedema and diminished vision } \\
\text { Left eye }\end{array}$ & $\begin{array}{l}\text { Diabetes } \\
\text { Mellitus }\end{array}$ & - do- & $\begin{array}{l}\text { Pre-op }-6 / 60 \\
\text { Post op }-6 / 36\end{array}$ & No & Free of disease \\
\hline 04 & $63 y$ & Male & 07 days & $\begin{array}{l}\text { Nasal obstruction, nasal } \\
\text { discharge, Hemifacial } \\
\text { headache, Periorbital oedema, } \\
\text { diminished vision, } \\
\text { conjunctival chemosis Right } \\
\text { eye, hemifacial swelling and } \\
\text { tenderness }\end{array}$ & $\begin{array}{l}\text { Diabetes } \\
\text { mellitus }\end{array}$ & -do & $\begin{array}{l}\text { Pre-op }-6 / 36 \\
\text { Post }- \text { op }-6 / 24\end{array}$ & No & $\begin{array}{l}\text { Recurrence of } \\
\text { disease within one } \\
\text { month of completion } \\
\text { of treatment. Treated } \\
\text { further with } \\
\text { Liposomal } \\
\text { Amphotericin B. } \\
\text { Responded well. } \\
\text { Presently free of } \\
\text { disease. }\end{array}$ \\
\hline 05 & $58 \mathrm{y}$ & Male & 06 days & $\begin{array}{l}\text { Hemifacial swelling and pain, } \\
\text { Nasal obstruction. Headache, } \\
\text { periorbital oedema and loss of } \\
\text { vision Right eye }\end{array}$ & $\begin{array}{l}\text { Diabetes } \\
\text { mellitus }\end{array}$ & - do- & $\begin{array}{l}\text { Pre }- \text { op - only perception of light present } \\
\text { Post op- finger counting close to eye }\end{array}$ & No & - do- \\
\hline 06 & $71 \mathrm{y}$ & Male & 15 days & $\begin{array}{l}\text { Headache, fever, left nasal } \\
\text { obstruction, Periorbital } \\
\text { oedema Left, Opthalmoplegia. } \\
\text { Loss of vision left eye }\end{array}$ & $\begin{array}{l}\text { Diabetes } \\
\text { Mellitus }\end{array}$ & - do & $\begin{array}{l}\text { Pre op - No perception of light or } \\
\text { Pupillary reaction } \\
\text { Post- op - No improvement in vision }\end{array}$ & No & - do- \\
\hline
\end{tabular}


All patients underwent urgent endonasal endoscopic debridement using microdebrider under general anaesthesia. Clearance of maxillary, ethmoidal, frontal, and sphenoidal sinuses and removal of medial orbital wall was done. Necrosed remnants of inferior and middle turbinates were removed using microdebrider. The orbit was opened endoscopically and decompressed medially removing the orbital fat till medial rectus muscle. The entire lamina papyracea and medial part of roof of maxillary sinus was removed. Sphenoid sinus widened laterally up to medial and lateral optico-carotid recess. Frontal sinus opened widely up to the orbital apex. The basisphenoid was drilled in all cases and skull base to sphenoid roof to frontal recess was delineated. Debridement was done till healthy bleeding tissue was encountered. All patients postoperatively continued on Liposomal Amphotericin B in renal corrected dosages for two-three weeks. Apart of correction of underlying predisposing condition, regular endoscopic nasal toilet were performed to remove crusting and to examine sinus cavities for recurrence until healing occurred. Except one renal transplant patient with extensive orbital involvement and intracranial extension, whose condition continued to deteriorate and eventually expired due to sepsis, all other patients responded well to treatment. One patient on follow up after one month of completion of treatment complaint of pain and swelling over previously affected site. Endoscopic examination revealed widespread crusting, biopsy was taken which revealed recurrence of mycosis. He was further treated with liposomal Amphotericin B in renal corrected dosage for a further duration of ten days. Presently all other five patients are under monthly follow up with us. Follow up nasal endoscopy reveals well healed mucosal lined nasal and sinus cavities with no evidence of mucormycosis. Only two patients out of six, showed some benefit in their visual acuity. Salient features of patients and treatment outcome is summarised in Table 1.

\section{DISCUSSION}

Upper airway mucormycosis was first described in 1885 by Paltauf, who coined the term "mycosis mucorina", which eventually became "mucormycosis". In 1943, the more typical findings of advanced rhinocerebral mucormycosis, proptosis, and ophthalmoplegia were reported in a series of three fatal cases in patients with diabetic ketoacidosis." In 1955, Harris et al described the cure of mucormycosis.

Mucormycosis is a term used to refer to any fungal infections of the order Mucorales, which belongs to the class Zygomycetes. Most pathogenic species are members of the family Mucoraceae. Rhizopusoryzae is the predominant pathogen and accounts for $60 \%$ of all forms of mucormycosis and $90 \%$ of rhinocerebral cases of mucormycosis. Apohysomyces elegans is the most recently recognised agent which causes mucormycosis in an immunocompetent individual. ${ }^{1}$
Diabetics in ketoacidosis are disproportionately affected. In the largest single series to date of 126 patients with rhinocerebral mucormycosis, $70 \%$ were diabetic. ${ }^{3}$ Rhizopus organisms are found commonly involved in causing acute invasive fungal rhinosinusitis due to an active ketone reductase system which help it thrive in high glucose, acidotic conditions. Diabetics also have decreased phagocytic activity because of an impaired glutathione pathway.

A study has shown that dialysis and iron overload patients treated with deferoxamine $\mathrm{B}$ (DFO), an iron and aluminium chelator, are more susceptible to mucormycosis. ${ }^{5}$ Other risk factors which increase susceptibility of an individual to mucormycosis include neutropenia, systemic steroid therapy, protein-calorie malnutrition, solid organ and bone marrow transplant, immunodeficiency, leukaemia, and intravenous drug abuse which involve the risk of injecting spores of Mucorales with drugs of abuse and then present with space-occupying lesions of the central nervous system. ${ }^{1}$

The presenting symptom is fever, which occurred in less than half of individuals, followed by nasal ulceration or necrosis, periorbital or facial swelling, or decreased vision; each occurred in approximately one third of cases. Rigid endoscopic nasal examination should be performed on every immune-compromised patient who continues to have fever with or without localising signs despite appropriate broad spectrum parenteral antibiotics. Nasal endoscopy findings of discoloration, ulceration, and eschar formation mainly involving middle and inferior turbinates, are suggestive of invasive fungal rhinosinusitis. Almost $80 \%$ of patients develops a necrotic lesion on either the nasal or oral mucosa. ${ }^{1,6}$

Early detection of mucormycosis is essential and incorporates clinical suspicion with culture and microscopic examination of the specimens. Potassium hydroxide-calcofluor white method can be used immediately on culture aspirate material. Potassium hydroxide dissolves tissues, and an optic brightener (calcofluor white) binds to the cell wall of the hyphae. Fungal cell walls, including septations, fluorescence are viewed using a fluorescence microscope. ${ }^{7}$ A presumptive diagnosis of mucormycosis can be made histologically based on the broad ribbon-like hyphae, 10 to $20 \mu$ across, haphazardly branched, and the absence or paucity of hyphal septations. In contrast to most fungi, the etiologic agents of mucormycosis are readily seen with haematoxylin and eosin tissue stains. Special fungal stains, such as Gomori methenamine silver, can be helpful, although other fungal stains, such as periodic acid-Schiff and Gridley, stain mucor poorly. Once organism becomes invasive, it shows a marked predilection for vascular invasion. ${ }^{1-3}$

CT scan is initial investigation of choice. Fine-cut $(2 \mathrm{~mm})$ slices in the axial and coronal planes should be obtained 
in high-risk patients. Intravenous contrast is used if intracranial or intraorbital extension is suspected, but it is not necessary for most initial evaluations. Severe unilateral thickening of the nasal cavity mucosa has been shown to be the most consistent finding on CT, suggestive of underlying invasive fungal sinusitis. It has also been suggested that infiltration of the periantral fat planes may represent the earliest imaging evidence of mucormycosis. CT scans are helpful in defining individual variations in sinus architecture and possible periorbital and intracranial spread. ${ }^{2,6}$ MRI is superior to CT in delineating the intracranial extent of the disease and it may have a role in evaluating patients who demonstrate signs of intracranial invasion: altered mental status, orbital apex syndrome, seizure, or stroke. ${ }^{2}$

It is evident that prompt diagnosis and early initiation of management in form of surgical debridement with systemic antifungal therapy and correction of underlying predisposing risk factors, if possible; gives most promising results leading to decrease in morbidity and mortality. ${ }^{6,8}$ According to few recent studies if treatment with polyene antifungal is initiated within 5 days of diagnosis of mucormycosis, survival was markedly improved compared to late initiation of treatment. $(83 \%$ vs. $49 \%$ survival). ${ }^{9,10}$ Medical antifungal therapy for most patients who have mucormycosis consists of systemic amphotericin B at intravenous doses of 0.25 to 1.0 $\mathrm{mg} / \mathrm{kg} / \mathrm{d}$ to a total dose of 2 to $4 \mathrm{~g}$ over six to eight weeks. The use of amphotericin B is limited in some patients secondary to renal toxicity, and they may be candidates for liposomal amphotericin $\mathrm{B}$ at a concentration of 3 to $5 \mathrm{mg} / \mathrm{kg} / \mathrm{d}$. $^{2}$ Moreover, there is evidence available that treatment of mucormycosis with liposomal amphotericin B was associated with a $67 \%$ survival rate, compared to $39 \%$ survival when patients were treated with AmB. ${ }^{9,11}$

Fluconazole, voriconazole, and itraconazole have not been found to have reliable activity against mucormycosis. The reported in vitro minimum inhibitory concentration for $90 \%$ of organisms (MIC90) of posaconazole against the Mucormycotina has ranged from $1 \mu \mathrm{g} / \mathrm{mL}$ to $\geq 4 \mu \mathrm{g} / \mathrm{mL} .^{9,12}$ Furthermore, there is evidence of mucormycosis developing as a breakthrough infection while on posaconazole prophylaxis. ${ }^{13}$ In contrast, van Burik et al reported $60 \%$ response rates (45\% partial response, $15 \%$ complete response) for salvage therapy in patients with mucormycosis who were refractory to or intolerant of polyenes. ${ }^{14}$ Greenberg et al reported similar results. Hence, posaconazole is an option for salvage therapy for these infections. ${ }^{15}$ In a recent retrospective review from two institutions, combination polyene-caspofungin therapy was associated with significantly improved outcomes in patients with rhinoorbital and rhino-orbital-cerebral mucormycosis compared to polyenemonotherapy. ${ }^{16,17}$

Antifungals alone are not sufficient in the treatment of invasive fungal sinusitis as blood vessels thrombosis and tissue necrosis results in poor bio-availability of antifungals at site of infection. In our case series, aggressive endoscopic sinonasal debridement using microdebrider was performed on all patients who have biopsy-proven disease or any patient suspected of having fungal invasion. Microdebrider assisted endoscopic surgery facilitated in removal of necrotic tissue and also shortened the duration of surgery. This slowed the progression of the disease, reduced fungal load, and also provided a specimen for culture and histopathologic diagnosis. Debridement of the involved sinuses or structures was extended until clear bleeding margins were noticed. ${ }^{18,19}$ Endoscopic debridement is better than open surgery as it gives better and magnified visualisation of nasal cavity and sinuses, with equally good surgical control of disease and lesser morbidity to patient. The key point to note is extensive and wide clearance of sinuses as described in treatment section, which resulted in better control in infection and thereby preventing recurrence. All patients also had diminished or loss of vision on presentation, however only in two case (02/06) improvement in visual acuity noted post-surgery. This also emphasises towards prompt intervention from the onset of symptoms. It is evident in our series that lesser the duration of illness, better were the control rates. None of the patient in our case series warranted conversion to an open approach. ${ }^{20}$ Another advantage of endoscopic debridement is ease in further endoscopic examination, cleaning of crusts and residual disease, thus preventing recurrences. All patients were kept under stringent follow up with weekly rigid nasal endoscopy for first four weeks and then, and once a month for 6 months thereafter. ${ }^{8}$

With present status of quality of care the mortality rate in mucormycosis has been decreased up to $20 \%$. Identification of the fungal organism can also be an important predictor of survival. The overall mortality of patients infected with Mucor $(29 \%)$ is higher than in those infected with aspergillus (11\%), regardless of the patient's underlying condition. ${ }^{2,8}$

Complications of mucormycosis range from relatively benign to potentially fatal and are divided into three categories: local, orbital, and intracranial.

- Local- mucocele, pott's puffy tumor, and osteomylitis.

- Orbital- preseptal cellulitis, orbital cellulitis, subperiosteal cellulitis, orbital abscess , and

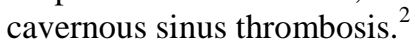

- Intracranial - meningitis, epidural abscess, subdural abscess, intracerebral abscess, and venous sinus thrombosis. $^{2,21}$

\section{CONCLUSION}

Mucormycosis is an aggressive fungal infection which can lead to fatal complications in immunocompromised patients if not managed promptly and energetically. Our 
experience shows that early detection of sinonasal mucormycosis in immunocompromised patients enables prompt aggressive treatment. Powered endoscopic debridement is efficient and feasible, leading to excellent local control and which ultimately led to reduced morbidity and mortality. In our experience with mucormycosis involving the sinonasal tract we could observe the few points. In the setting of uncontrolled diabetic patients if they have any unilateral eye symptom one should suspect mucormycosis as they are often missed out at this stage till they develop neurological features which is a late sign. The early the surgical intervention is offered in the form of endoscopic sinus clearance and medial orbital decompression the better are the results in controlling the disease progression and to have the chances of vision loss recovery.

The aggressive control of immune compromise status along with surgery and 4 weeks of amphoterin B drug can improve the mortality rates in such patients which happened in our cases

\section{ACKNOWLEDGMENTS}

This work was supported by Command Hospital (Southern Command), Pune. No other financial grants were received. We thank Department of Pathology, Command Hospital (Southern Command), Pune, India for providing histopathological studies. We thank the physicians who provided clinical information. We also thank the patients and their families.

\section{Funding: Command Hospital (Southern Command), Pune, India \\ Conflict of interest: None declared \\ Ethical approval: Not required}

\section{REFERENCES}

1. Ferguson BJ. Mucormycosis of the nose and paranasal sinuses. Otolaryngol Clin North Am. 2000; 3(2):349-65.

2. Epstein VA, Kern RC. Invasive fungal sinusitis and complications of rhinosinusitis. Otolaryngol Clin North Am. 2008;41(3):497-524.

3. Strasser MD, Kennedy RJ, Adam RD. Rhinocerebral mucormycosis: therapy with amphotericin B lipid complex. Arch Intern Med. 1996;156(3):337-9.

4. Harris JS. Mucormycosis. Pediatrics. 1955;16(6):857-67.

5. De Locht M, Boelaert JR, Schneider YJ. Iron uptake from ferrioxamine and from ferrirhizoferrin by germinating spores of Rhizopus microsporus. Biochem Pharmacol. 1994;47(10):1843-50.

6. Gillespie MB, O’Malley BW. An algorithmic approach to the diagnosis and management of invasive fungal rhinosinusitis in the immunocompromised patient. Otolaryngol Clin North Am. 2000;33(2):323-34.

7. Schell WA. Histopathology of fungal rhinosinusitis. Otolaryngol Clin North Am. 2000; 33(2):251-76.

8. Parikh SL, Venkatraman G, DelGaudio JM. Invasive fungal sinusitis: a 15-year review from a single institution. Am J Rhinol. 2004;18(2):75-81.

9. Spellberg B, Ibrahim AS. Recent advances in the treatment of mucormycosis. Curr Infect Dis Rep. 2010;12(6):423-9.

10. Chamilos G, Lewis RE, Kontoyiannis DP. Delaying amphotericin B-based frontline therapy significantly increases mortality among patients with hematologic malignancy who have zygomycosis. Clin Infect Dis. 2008;47:503-9.

11. Gleissner B, Schilling A, Anagnostopolous I, Siehl I, Thiel E. Improved outcome of zygomycosis in patients with hematological diseases? Leuk Lymphoma. 2004;45(7):1351-60.

12. Sun QN, Fothergill AW, McCarthy DI, Rinaldi MG, Graybill JR. In vitro activities of posaconazole, itraconazole, voriconazole, amphotericin $\mathrm{B}$, and fluconazole against 37 clinical isolates of zygomycetes. Antimicrob Agents Chemother. 2002;46(5):1581-2.

13. Trifilio S, Bennett C, Yarnold P, et al. Breakthrough zygomycosis after voriconazole administration among patients with hematologic malignancies who receive hematopoietic stem-cell transplants or intensive chemotherapy. Bone Marrow Transplant. 2007;39(7):425-9.

14. van Burik J-AH, Hare RS, Solomon HF, Corrado ML, Kontoyiannis DP. Posaconazole is effective as salvage therapy in zygomycosis: a retrospective summary of 91 cases. Clin Infect Dis. 2006;42(7):61-5.

15. Greenberg R, Mullane K, Van Burik JA, Raad I, Abzug MJ, Anstead G, et al. Posaconazole as salvage therapy for zygomycosis. Antimicrob Agents Chemother. 2006;50(1):126-33.

16. Ibrahim AS, Bowman JC, Avanessian V, Brown K, Spellberg B, Edwards JE Jr, et al. Caspofungin inhibits Rhizopus oryzae 1, 3- $\beta$-D-glucan synthase, lowers burden in brain measured by quantitative PCR, and improves survival at a low but not a high dose during murine disseminated zygomycosis. Antimicrob Agents Chemother. 2005;49(2):721-7.

17. Reed C, Bryant R, Ibrahim AS, Edwards J Jr, Filler $\mathrm{SG}$, Goldberg $\mathrm{R}$, et al. Combination polyenecaspofungin treatment of rhino-orbital-cerebral mucormycosis. Clin Infect Dis. 2008;47(3):364-71.

18. Kennedy CA, Adams GL, NEGLIA JP, Giebink GS. Impact of surgical treatment on paranasal fungal infections in bone marrow transplant patients. Otolaryngol Head Neck Surg. 1997;116(6):610-6. 
19. O'Brien M, Chapin K, Soto-Aguilar M, Gardner L, Swain R. A new classification and diagnostic criteria for invasive fungal sinusitis. Arch Otolaryngol Head Neck Surg. 1997;123(11):1181-8.

20. Avet PP, Kline LB, Sillers MJ. Endoscopic Sinus Surgery in the Management of Mucormycosis. J Neuroophthalmol. 1999;19:56-61.

21. Goldberg AN, Oroszlan G, Anderson TD. Complications of frontal sinusitis and their management. Otolaryngol Clin North Am. 2001;34(1):211-25.

Cite this article as: Singh I, Gupta V, Gupta SK, Goyal S, Kumar M, Singh A. Our experience in endoscopic management of mucormycosis: a case series and review of literature. Int J Otorhinolaryngol Head Neck Surg 2017;3:465-71. 